\title{
PERUBAHAN PENGGUNAAN LAHAN DI KECAMATAN KELARA DAN RUMBIA KABUPATEN JENEPONTO
}

\author{
Land Use Changes in Kelara and Rumbia District, Jeneponto
}

${ }^{1 *}$ Firman Sutomo

${ }^{1}$ Prodi Ilmu Tanah Fakultas Pertanian, Peternakan, dan Kehutanan, Universitas Muslim Maros, Maros

"Corresponding email; firmansutomo96@gmail.com

\begin{abstract}
Land use that is incompatible with the function of land can lead to negative effects, therefore it is necessary to set the direction of land use change in land use. This study aims to determine the dynamics of land use during the period of 15 years (1999-2013) and determine the fit between the spatial patterns of spatial plans with the actual land use in Rumbia and Kelara, Jeneponto. The study was conducted through data collection and analysis of data, the data used include primary data and secondary data obtained through observation, field observations, and other supporting data. Data already collected subsequently analyzed by using descriptive and quantitative analysis by means of data interpretation and overlay maps with GIS systems. The results of the study show that obtained six classes of land use consisting of forests, gardens, settlements, rice fields, shrubs and moorings / fields indicate that land use has decreased by $2.66 \%$ in 1999, 2004 by $1,44 \%$, and in 2013 decreased to $1.09 \%$ and those that experienced an increase in area were fields / fields of 50.44\% in 1999, in 2004 it increased to $62.10 \%$, and in 2013 the area increased to $69.52 \%$.
\end{abstract}

Keywords: land use change, pattern space, spatial

\section{PENDAHULUAN}

Lahan merupakan suatu sistem yang kompleks sehingga membutuhkan penataan secara baik. Dalam pengelolaan lahan, harus dapat dibedakan secara seksama antara lahan sebagai sumber daya (resources) dan lahan sebagai lingkungan (environment). Sehingga, dalam penatagunaan lahan, diperlukan aktivitas-aktivitas yang dapat memperkaya hubungan-hubungan yang menguntungkan serta meminimalisasi, dan mengupayakan tercapainya keadaan sistem lingkungan yang diinginkan (Baja, S. 2012 ).

Penggunaan lahan secara umum (major kinds of land use) adalah penggolongan penggunaan lahan seperti pertanian tadah hujan, pertanian berigrigasi, padang rumput, kehutanan, atau daerah rekreasi. Penggunaan lahan secara umum biasanya digunakan untuk evaluasi lahan secara kualitatif atau dalam survei tinjau (reconaissance). Tipe penggunaan lahan (land utilization type) secara terperinci adalah tipe penggunaan lahan sesuai dengan syarat-syarat teknis untuk suatu daerah dengan keadaan fisik dan sosial ekonomi tertentu. Penggunaan lahan secara terperinci (tipe penggunaan lahan) dapat terdiri dari: (1) hanya 1 jenis tanaman, dan (2) lebih dari satu jenis tanaman. Tipe penggunaan lahan yang kedua ini dibedakan lagi menjadi: (a) tipe penggunaan lahan ganda (multiple land utilizaton type), adalah penggunaan lahan dengan lebih dari satu jenis sekaligus, dimana masing-masing jenis memerlukan input, syarat-syarat dan memberikan hasil yang berbeda. Sebagai 
contoh, daerah hutan produksi yang sekaligus digunakan untuk daerah rekreasi dan (b) tipe penggunaan lahan majemuk (compound land utilizaton type). Tipe penggunaan lahan majemuk adalah penggunaan lahan dengan lebih dari satu jenis, tetapi untuk tujuan evaluasi dianggap sebagai satu satuan) misalnya sistem pertanian tumpang sari mixed farming (Hardjowigeno dan Widiatmaka, 2011).

Kemajuan pembangunan di suatu wilayah sejalan dengan peningkatan jumlah pertumbuhan penduduk yang diiringi meningkatnya standar kualitas dan kuantitas kebutuhan hidup. Dampak dari peningkatan standar kualitas dan kuantitas hidup tersebut mengakibatkan peningkatan kebutuhan lahan untuk memenuhi kebutuhan hidup tersebut terjadi proses perubahan penggunaan lahan yang merubah tata guna lahan. Setiap macam penggunaan tanah mempunyai pengaruh yang berbeda terhadap kerusakan tanah oleh erosi. Macam penggunaan tanah pertanian ditentukan oleh jenis tanaman, cara bercocok tanam, dan intensitas penggunaan lahan. Teknologi yang diterapkan pada setiap macam penggunaan tanah akan menentukan apakah akan didapat penggunaan dan produksi yang lestari dari sebidang tanah (Arsyad, 2010).

Perubahan penggunaan lahan dalam pelaksanaan pembangunan tidak dapat dihindari. Perubahan tersebut terjadi karena dua hal, pertama adanya keperluan untuk memenuhi kebutuhan penduduk yang makin meningkat jumlahnya dan kedua berkaitan dengan meningkatnya tuntutan akan mutu kehidupan yang lebih baik (Haryani, P. 2011). Perubahan penggunaan lahan diartikan sebagai suatu proses perubahan dari penggunaan lahan sebelumnya ke penggunaan lahan lainnya yang dapat bersifat permanen maupun sementara, dan merupakan bentuk konsekuensi logis adanya pertumbuhan dan transformasi perubahan struktural ekonomi masyarakat yang sedang berkembang (Niin, 2010). Pengelolaan yang terintegrasi perlu didukung oleh data/informasi dasar tentang kondisi fisik suatu lahan. Data yang multiwaktu juga sangat bermanfaat untuk memperkirakan laju dan arah terjadinya perubahan, sehingga kegiatan antisipasi dapat segera dilakukan. Mengingat laju perubahan suatu lahan yang begitu cepat maka data yang dibutuhkan adalah data terbaru yang dapat diperoleh secara cepat, akurat dan efisien. Dalam kaitannya sebagai pengumpul data serta pendeteksian perubahan-perubahan tersebut, penginderaan jauh memegang peranan yang sangat penting karena mampu memberikan informasi secara lengkap, cepat, dan relative akurat. Pemanfaatan lahan maupun alih guna lahan akan memberikan implikasi yang cukup luas terhadap keragaan perekonomian wilayah, alokasi sumberdaya dan tenaga kerja serta struktur tataruang wilayah (Utoyo, B. 2012).

Hasil penelitian Fitriah D (2011), selama periode tahun 2005-2010 terjadi perubahan penggunaan lahan seluas 6.692 hektar atau 30,6\% dari luas wilayah Kota Bima, sementara yang tidak mengalami perubahan adalah seluas 15.171 hektar atau $69,4 \%$

dari luas wilayah Kota Bima. Hutan primer yang pada tahun 2005 masih terdapat seluas 283 hektar, pada tahun 2010 telah hilang sama sekali berubah menjadi pertanian lahan kering, padang rumput penggembalaan ternak, sawah dan semak belukar.

Pada tahun 1991, luas hutan di TNGHS mencapai 60.825,78 ha. Kelas hutan mengalami penurunan jumlah luasannya menjadi 49.234,23 ha atau sekitar 11,04\% pada tahun 1997. Pada saat yang sama, kelas yang mengalami peningkatan adalah kelas semak/belukar dari 17.699,94 ha pada tahun 1991 menjadi 27.302,13 ha pada tahun 1997. Sedangkan pada tahun 2001 jumlah luas hutan semakin berkurang menjadi 42.552,9 ha. Areal hutan banyak dikonversi menjadi semak/belukar, rumput/tanah kosong, 
pemukiman, kebun/perkebunan, dan tegalan/ladang yang telah menuju ke arah TNGHS. Kelas sawah mengalami penurunan pada kurun waktu 1997-2001, yaitu sebesar 3.249,81 ha atau 3,15\%. Penurunan jumlah luasan ini sejalan dengan penggunaan areal sawah yang berkaitan dengan kebutuhan masyarakat akan perumahan, dimana areal sawah ini banyak yang dijadikan pemukiman. Terjadi penambahan luas areal untuk kelas pemukiman sebesar 911,61 ha (Hermawan Irwan, 2008).

Kabupaten Jeneponto mempunyai luas wilayah $74.979 \mathrm{~km}^{2}$ dengan jumlah penduduk pada tahun 2010 sebesar 342.700 jiwa dan tahun 2012 sebesar 348.138 jiwa. Jumlah penduduk pada kecamatan Rumbia pada tahun 2010 yaitu 22.634 jiwa dan tahun 2012 sebesar 22.993 jiwa dan Kelara pada tahun 2010 yaitu 26.440 jiwa dan tahun 2012 sebesar 26.860 jiwa. Berdasarkan luas wilayah menurut kecamatan, luas Kecamatan Rumbia $58.30 \mathrm{~km}^{2}$ (7.78\%), dan Kelara 43.95 $\mathrm{km}^{2}(5.86 \%)$. Jenis penggunaan lahan yang luas di Kecamatan Rumbia adalah tegalan sebesar 3.572 ha, sawah 1.357 ha, dan perkebunan 357 ha. Sedangkan jenis penggunaan lahan yang luas di Kecamatan Kelara adalah tegalan sebesar 3.282 ha, sawah 704 ha, dan perkebunan 268 ha (BPS, 2012).

Analisis perubahan penggunaan lahan dengan memanfaatkan data spasial yang bersifat temporal sangat bermanfaat, khususnya untuk mengetahui lokasi-lokasi tempat dimana perubahan penggunaan lahan terjadi. Selain itu pemanfaatan Sistem Informasi Geografi (SIG) yang dapat mengintegrasikan data spasial dan data keruangan ternyata mampu menghasilkan data atribut yang bisa digunakan sebagai acuan dalam analisis statistik yang bisa digunakan untuk memprediksi luasan penggunaan lahan di masa datang. Penelitian ini bertujuan untuk mengetahui perubahan penggunaan lahan selama kurun waktu tahun
15 tahun (tahun 1999-2013) di Kecamatan Rumbia dan Kelara Kabupaten Jeneponto.

\section{METODOLOGI}

\section{Lokasi penelitian}

Penelitian ini dilaksanakan di Kecamatan Kelara dan Kecamatan Rumbia Kabupaten Jeneponto.

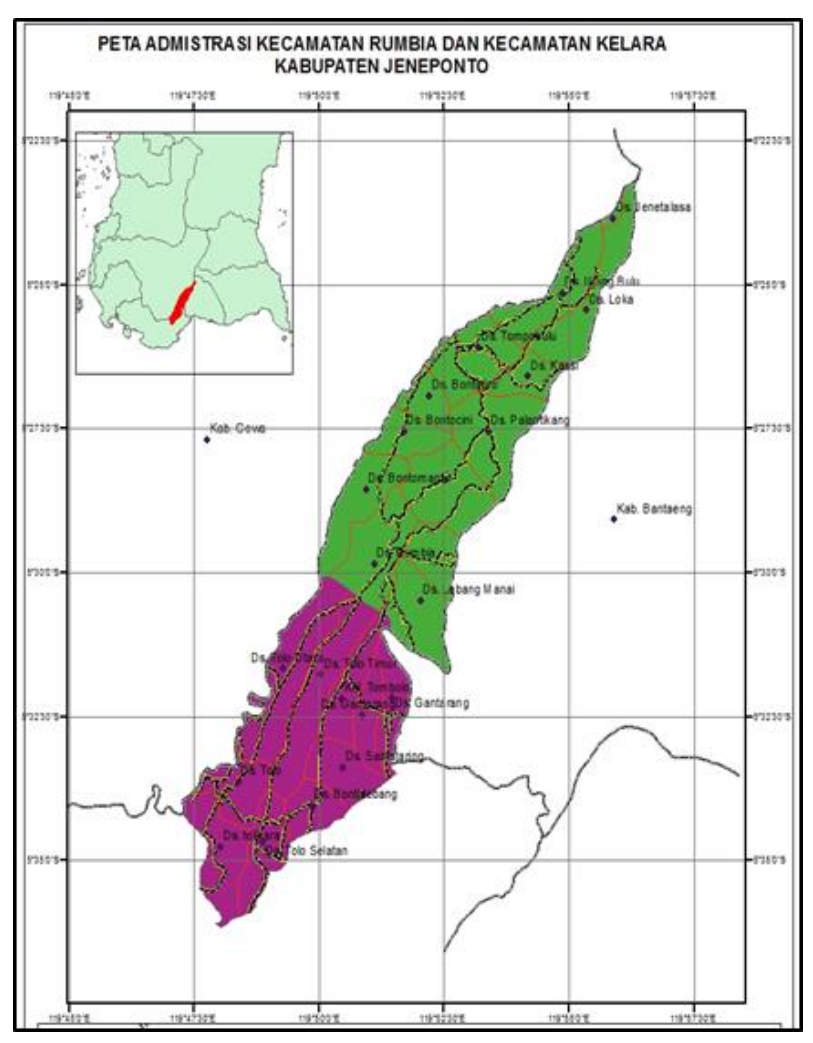

Gambar 1. Peta Lokasi Penelitian

\section{Pengumpulan Data}

Penelitian dilakukan melalui pengumpulan data dan analisis data. Jenis data terdiri atas data Primer yang langsung dikumpulkan atau diperoleh dari hasil pengukuran dilapangan yaitu citra landsat times series tahun 1999, 2004 dan 2013 dan data Sekunder yang diperoleh dari studi kepustakaan yaitu peta rupa bumi (RBI), peta batas administrasi Kabupaten Jeneponto, peta RTRW Kabupaten Jeneponto Tahun 2010-2030, serta beberapa 
peta penunjang lainnya yang diperoleh dari Badan Perencanaan Pembangunan Daerah (BAPPEDA) Kabupaten Jeneponto.

\section{Analisis data}

Data yang sudah terkumpul selanjunya dianalisis dengan menggunakan teknik analisis spasial dengan cara pengolahan citra dan overlay peta dengan sistem SIG. Hasil analisis di wujudkan dalam bentuk peta dan tabel masing-masing kawasan penggunaan lahan yang memperlihatkan perubahan penggunaan lahan. Identifikasi wilayah dilakukan melalui proses antara lain, (1). Mengoverlay peta penggunaan lahan 19992004 dan (2) Mengoverlay peta penggunaan lahan tahun 2004-2013.

\section{HASIL DAN PEMBAHASAN}

\section{Hasil}

Berdasarkan hasil analisis citra diperoleh enam kelas penggunaan lahan di Kecamatan Kelara dan Rumbia Kabupaten Jeneponto terdiri atas hutan, kebun, pemukiman, sawah, semak belukar dan tegalan/ladang. Luas penggunaan lahan disajikan pada Tabel 1 .

\section{PEMBAHASAN}

Penelilitian ini menunjukkan bahwa penggunaan lahan hutan dan kebun campuran mengalami penurunan yang signifikan. Semak belukar mengalami penurunan luas dari tahun 2004 sampai dengan tahun 2013. Sawah bervariasi berubah pada tiap periode tahun. Pemukiman dan tegalan/ladang secara signifikan terus mengalami peningkatan. Penggunaan lahan pada Kecamatan Kelara dan Rumbia cenderung mengalami perubahan luas areal dari tahun ke tahun. Penggunaan lahan terluas di Kecamatan Kelara dan Rumbia pada tahun 1999 adalah tegalan/ladang sebesar 50,44 \%, pada tahun 2004 bertambah menjadi $62,10 \%$, dan pada tahun 2013 luas areal bertambah menjadi $69,52 \%$. Penggunaan lahan pemukiman pada tahun 1999 seluas 1,86 \%, tahun 2004 seluas 3,45\%, dan tahun 2013 bertambah menjadi $6,05 \%$ sedangkan penggunaan lahan yang mengalami pengurangan luas areal adalah hutan sebesar 2,66 \% pada tahun 1999, tahun 2004 seluas 1,44 \%, dan tahun 2013 menurun menjadi $1,09 \%$.

Tabel 1. Luas Penggunaan Lahan Tahun 1999, 2004, dan 2013

\begin{tabular}{lcccccc}
\hline \multirow{2}{*}{ Penggunaan Lahan } & \multicolumn{2}{c}{ Tahun 1999 } & \multicolumn{2}{c}{ Tahun 2004 } & \multicolumn{2}{c}{ Tahun 2013 } \\
\cline { 2 - 7 } & Ha & $\%$ & Ha & $\%$ & Ha & $\%$ \\
\hline Hutan & 276.44 & 2.66 & 149.40 & 1.44 & 113.04 & 1.09 \\
Kebun Campur & 912.25 & 8.76 & 591.88 & 5.69 & 187.41 & 1.80 \\
Pemukiman & 194.05 & 1.86 & 358.86 & 3.45 & 630.00 & 6.05 \\
Sawah & 3090.56 & 29.69 & 2176.18 & 20.91 & 2181.62 & 20.96 \\
Semak Belukar & 685.46 & 6.59 & 668.28 & 6.42 & 60.35 & 0.58 \\
Tegalan/Ladang & 5249.53 & 50.44 & 6463.68 & 62.10 & 7235.86 & 69.52 \\
\multicolumn{1}{c}{ Total } & 10408.28 & 100 & 10408.28 & 100 & 10408.28 & 100 \\
\hline \multicolumn{1}{c}{} & & & & & &
\end{tabular}




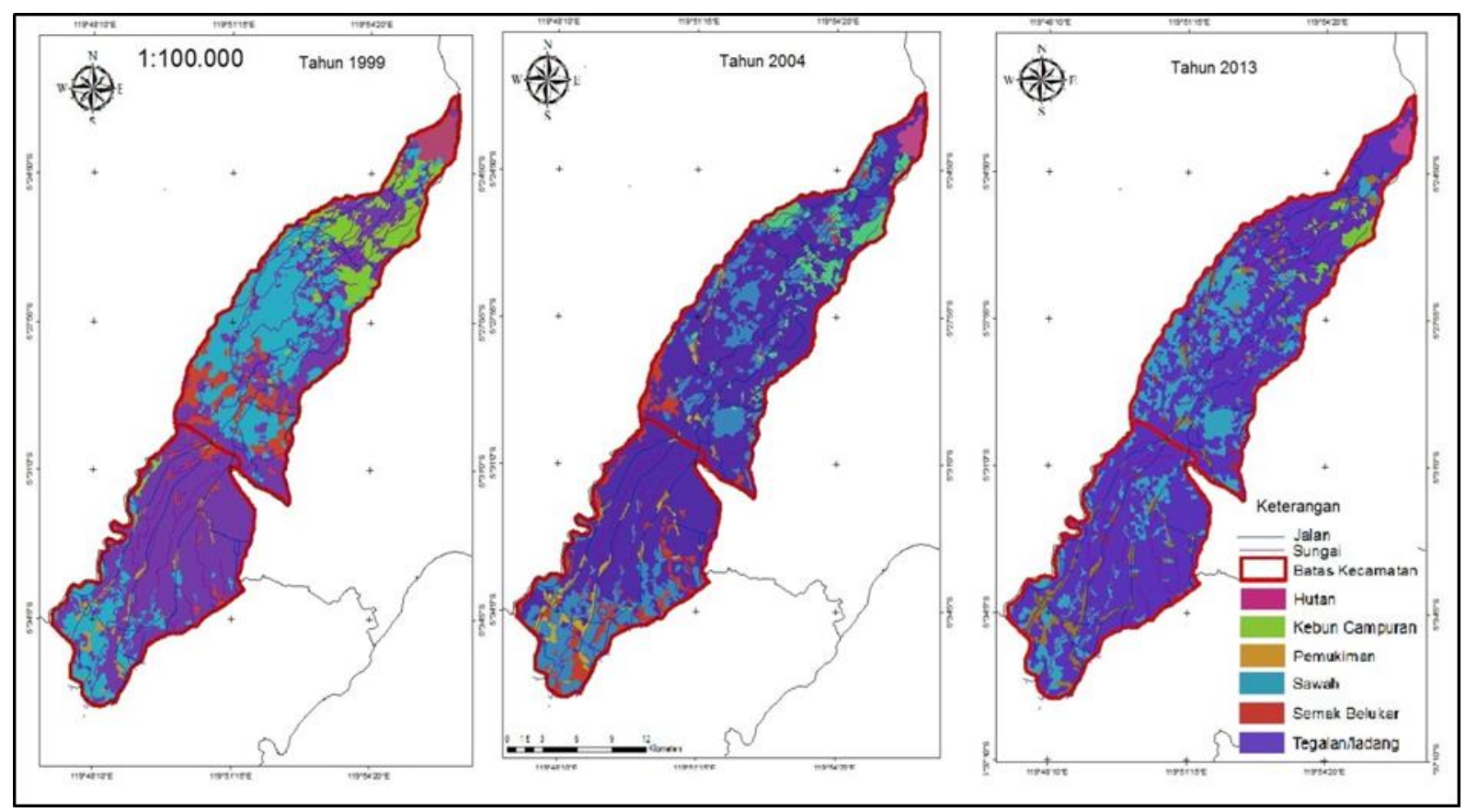

Gambar 2. Penggunaan Lahan tahun 1999, 2004, dan 2013.

Perubahan hutan menjadi tegalan/ladang merupakan perubahan dengan luasan yang paling tinggi. Hal ini menunjukkan bahwa kebutuhan lahan untuk pertanian lahan kering semakin meningkat, sehingga konversi lahan hutan menjadi non hutan cenderung meningkat. Salah satu dampak perubahan lahan hutan yaitu dapat menyebabkan banjir. Hal ini dapat dilihat apabila terjadi hujan maka kecepatan energi kinetis air hujan mengenai permukaan tanah akan semakin cepat sehinga dapat menghancurkan lapisan di atas permukaan tanah (humus) yang merupakan daerah resapan air. Kerusakan lapisan humus menyebabkan tidak ada yang menahan air hujan sehingga air hujan tersebut akan langsung mengalir dan melebihi daya tampung badan air sehingga sering kali menyebabkan banjir. Perubahan fungsi hutan ini juga akan mengarah pada kondisi yang tidak diinginkan yaitu berupa peningkatan erosi dan sedimentasi, penurunan produktivitas lahan, dan degradasi hutan (Hermawan I, 2008).

Penurunan luas kebun campuran dari periode tahun 2004 sampai dengan tahun 2013 adalah sebesar 187,41 ha atau sekitar 1,80\%. Hal ini disebabkan karena kebun campuran beralih fungsi menjadi pemukiman, sawah dan tegalan/ladang. Menurut de la Cretaz and Barten (2007) perubahan penggunaan lahan dari lahan terbuka (hutan, kebun atau tegalan) menjadi lahan untuk pemukiman menyebabkan infiltrasi air permukaan berkurang, meningkatkan aliran permukaan, dan pengisian kembali air tanah menjadi berkurang.

Peningkatan luas pemukiman dari periode tahun 2004 sampai dengan tahun 2013 adalah sebesar 630 ha atau sekitar 6,05\%. Peningkatan ini cukup besar karena desakan pertumbuhan penduduk di Kecamatan Kelara dan Rumbia. Hal ini dapat dipahami selain merupakan dampak dari pertumbuhan penduduk, juga disebabkan karena perkembangan perekonomian masyarakat. 
Dengan berkembangnya kegiatan perekonomian di dalam ruang (space), sudah barang tentu pemilihan lokasi yang strategis baik dilihat dari kualitas maupun aksesibilitas yang dimiliki lahan untuk dikonsumsi maupun berproduksi merupakan hal yang penting. Kondisi demikian ini pada gilirannya akan menimbulkan semakin kompleksnya persaingan (konflik) penggunaan lahan di wilayah yang bersangkutan karena adanya berbagai kepentingan yang melatar belakanginya (Utoyo 2012). Konversi lahan pertanian dengan tanah subur termasuk sawah irigasi menjadi lahan non-pertanian seperti wilayah industri, perumahan perlu ditata karena sulitnya mencari lahan pengganti yang lebih subur atau minimal sama, di luar lahan pertanian yang telah ada (Hardjowigeno et al., 2007).

Perubahan penggunaan lahan adalah bertambahnya suatu penggunaan lahan dari satu sisi penggunaan ke penggunaan yang lainnya diikuti dengan berkurangnya tipe penggunaan lahan yang lain dari suatu waktu ke waktu berikutnya, atau berubahnya fungsi suatu lahan pada kurun waktu yang berbeda. Perubahan penggunaan lahan dapat mempengaruhi sistem ekologi setempat diantaranya pencemaran air, polusi udara, perubahan iklim lokal, berkurangnya keanekaragaman hayati, dinamika aliran nitrat , serta fluktuasi pelepasan dan penyerapan CO 2 (A.R. Assyakur,dkk.2008).

\section{KESIMPULAN}

Berdasarkan hasil penelitian dapat disimpulkan bahwa hasil analisis citra dengan komposit band 542 diperoleh enam penggunaan lahan yaitu hutan, pemukiman, kebun campur, sawah, semak belukar, dan tegalan/ladang.

Penggunaan lahan yang mengalami peningkatan perubahan luas areal pada tahun 1999-2004 adalah pemukiman sebesar 3.45
$\%$, semak belukar $6.42 \%$, dan tegalan/ladang $62.10 \%$. Penggunaan lahan yang mengalami penurunan luas areal adalah hutan sebesar $1.44 \%$, kebun campur 5.69\%, dan sawah $20.91 \%$.

Penggunaan lahan yang mengalami peningkatan perubahan luas areal pada tahun 2004-2013 adalah pemukiman sebesar 6.05 $\%$, sawah $20.96 \%$, dan tegalan/ladang. 69.52 $\%$ Penggunaanlahan yang mengalami penurunan luas areal adalah hutan $1.09 \%$, kebun campuran $1.80 \%$, dan semak belukar $0.58 \%$.

\section{DAFTAR PUSTAKA}

Arsyad, S. 2010. Konservasi Tanah dan Air. IPB Press.Bogor.

A.R. As-syakur, I W. Suarna, I W.S. Adnyana, I W. Rusna, I.A.A. Laksmiwati, I W. Diara.2008. Studi Perubahan Penggunaan Lahan Di Das Badung. Jurnal. Fakultas Pertanian Universitas Udayana.
Badan Perencanaan Pembangunan Daerah Kabupaten Jeneponto. 2010. RTRW Kabupaten Jeneponto 2010- 2013. Jeneponto.

Badan Pusat Statistik Kabupaten Jeneponto. 2012. Jeneponto Dalam Angka. Jeneponto.

Baja, S. 2012. Perencanaan Tata Guna Lahan Dalam Pengembangan Wilayah Pendekatan Spasial dan Aplikasinya. CV.Andi Offset. Yogyakarta.

de la Crétaz, A.L. and P.K. Barten. 2007. Land Use Effects on Streamflow and Water Quality in the Northeastern United States. CRC Press. FloridaUSA. 
Fitriah, D. 2011. Perubahan penggunaan lahan dan pengaruhnya terhadap daya dukung lahan untuk mendukung perencanaan penataan Ruang (Studi Kasus di Kota Bima Provinsi Nusa Tenggara Barat). Tesis. Institut Pertanian Bogor. Bogor

Hardjowigeno, S., dan Widiatmaka. 2011. Evaluasi Kesesuaian Lahan dan Perencanaan Tata Guna Tanah. Gadjah Mada University Press. Yogyakarta.

Haryani, P. 2011. Perubahan Penutup/Penggunaan Lahan dan Perubahan Garis Pantai di DAS Cipunagara dan sekitarnya. Skripsi. Institut Pertanian Bogor. Bogor.

Hermawan, Irwan. 2008. Deteksi Perubahan Penutupan Lahan Di Taman Nasional Gunung Halimun Salak Menggunakan Citra Landsat Multiwaktu (Skripsi). Fakultas Kehutanan Institut Pertanian Bogor. Bogor.

Niin. 2010. Dinamika Spasial Penggunaan Lahan di Kabupaten Katingan dan Kota Palangka Raya Provinsi Kalimantan Tengah. Tesis. Pascasarjana Institut Pertanian Bogor. Bogor.

Utoyo S, 2012. DinamikaPenggunaanLahan di Wilayah Perkotaan (Studi di Kota Bandar Lampung).Seminar HasilHasil Penelitian dan Pengabdian Kepada Masyarakat Dies Natalis FISIP Unila. 